\title{
Efeitos de um Programa de Ensino de Discriminação de Categorias Estruturais Implícitas de Histórias em Crianças
}

\author{
Effects of a Teaching Program on the Discrimination of Implicit \\ Story Categories in Children
}

\author{
Ana Carolina Sella*, $a$, Daniela Mendonça Ribeiro ${ }^{b}$, Carmen Silvia Motta Bandinic, \\ Heloísa Helena Motta Bandinic \& Fernanda M${ }^{\mathrm{a}}$. S. do Bomfim ${ }^{c}$ \\ ${ }^{a}$ University of Nebraska Medical Center, Omaha, Nebrasca, Estados Unidos, \\ ${ }^{b}$ Universidade Federal de São Carlos, São Carlos, São Paulo, Brasil \\ \& ${ }^{c}$ Universidade Estadual de Ciências da Saúde do Alagoas, Maceió, Alagoas, Brasil
}

\begin{abstract}
Resumo
Pesquisas mostram a importância de se identificar categorias estruturais na formação de um repertório efetivo de contação de histórias. Consequentemente, procedimentos de ensino de identificação destas categorias vêm sendo desenvolvidos. O objetivo do presente manuscrito, o qual consiste em dois estudos, foi investigar os efeitos de um procedimento de ensino de identificação de categorias de histórias em 12 crianças (seis em cada estudo), com idades entre oito e 12 anos. Foi empregado um delineamento de sondas múltiplas, caracterizado pela avaliação do desempenho de cada participante antes e após o ensino de cada categoria. O ensino foi dividido em duas etapas, descrição e identificação de cada categoria, nas quais foram apresentadas instruções orais e escritas, assim como diferentes histórias. Em ambos os estudos, o procedimento resultou na aprendizagem de todas as categorias pelos participantes. Os estudos contribuem com a literatura acerca do ensino da discriminação de categorias estruturais de histórias.

Palavras-chave: Categorias implícitas, estrutura de história, discriminação de categorias, instrução programada.

Abstract

Research has shown the importance of identifying story structure categories in the development of an effective storytelling repertoire. Consequently, procedures that aim at teaching the identification of those categories have been developed and tested. The purpose of the present manuscript, which encompasses two studies, was to assess the effects of a teaching procedure for story category identification in 12 children ( six in each study), ages ranging from eight to 12 years. A multiple probe design, which is comprised by probes of participants' performance before and after each category teaching, was used. Teaching sessions were divided in two phases - description and identification of each category - which consisted in the presentation of oral and written instructions and different stories. In both studies, the procedure yielded the learning of all categories by every participant. The studies contribute to the literature on teaching story structure category discrimination.

Keywords: Implicit categories, story structure, category discrimination, programmed instruction.
\end{abstract}

Teóricos de diversas áreas, incluindo educação, saúde e artes, afirmam que a importância da habilidade de contar histórias está no fato destas possuírem funções multifacetadas e refletirem uma grande variedade de relações que baseiam o comportamento social humano (Ballard \& Glynn, 1975; Banks-Wallace, 1999; Koki, 1998; Stein, 1982). Neste sentido, a importância das histórias está nas mais diversas atividades humanas, como na escrita e no relato oral de narrativas em geral, tais como eventos co-

\footnotetext{
* Endereço para correspondência: University of $\mathrm{Ne}$ braska Medical Center, 668 S. 41st, Omaha, NE, United States68105. Email: carolsella@yahoo.com.br
}

tidianos, histórias, capítulos de novela, alguns conteúdos escolares e, até mesmo, tópicos científicos (Aulete, 2006; Stein, 1982). Ao destacarem a importância da presença do (re)contar histórias no cotidiano, autores como Glover (1979) e Ribeiro, Pascualon, Sella, Bandini e de Souza (2009), entre outros, ressaltam a necessidade de programação sistematizada de ensino para o aprendizado de tais repertórios.

Nesta perspectiva, Maranhe (2004) e Spinillo e Simões (2003), entre outros, descreveram as chamadas categorias estruturais de história, apresentadas por Mandler e Johnson (1977), como estímulos relevantes para a construção de um repertório de (re)contar histórias. Apesar das muitas 
diferentes definições, estas categorias podem ser divididas, de uma forma geral, em: Cenário (indicação de local, tempo e personagens da história), Tema (problema central a ser resolvido ao longo da história), Enredo (ações dos personagens para resolver seus problemas), Resolução (solução do problema ou desfecho da história) e Seqüência (ordenação dos fatos ao longo do relato que inclui as demais categorias).

Sob a perspectiva da Análise do Comportamento, a habilidade de (re)contar histórias envolve o controle adequado por estímulos relevantes do ambiente, assim como outros repertórios que envolvem comportamentos complexos (Bandini, Sella, \& de Souza, 2006; Ribeiro et al., 2009).

Buscando estabelecer o controle do recontar histórias por estímulos discriminativos relevantes (categorias), Maranhe (2004) propôs um programa de ensino de recontagem de histórias, o qual, primeiramente, consistiu no ensino da definição e da identificação das categorias estruturais, sendo seguido por um teste de recontagem. Posteriormente, Bandini et al. (2006) sistematizaram o procedimento de ensino proposto por Maranhe (2004), estabelecendo parâmetros para as instruções e para a apresentação de tentativas. Para isso, utilizaram um delineamento de linha de base múltipla entre categorias, com apresentação individual das instruções de ensino. Após apresentarem um procedimento de definição/identificação das categorias estruturais de histórias a 8 crianças com idades entre 9 e 12 anos, as autoras analisaram variáveis ligadas ao planejamento do procedimento que possivelmente levaram a algumas instâncias de controle espúrios de estímulos sobre as respostas de identificação de categorias. O procedimento de ensino previa que, primeiramente, os participantes discriminassem a definição de uma dentre quatro categorias estruturais de história (cenário, tema, enredo e resolução) e, a seguir, identificassem aquela categoria que era considerada a resposta correta dentro do contexto das atividades contidas no estudo. Assim, as sessões de ensino foram constituídas das seguintes etapas: (a) definição das categorias, na qual a experimentadora descrevia a categoria a ser ensinada e, em seguida, lia uma história exemplo para identificar a categoria em questão junto com o participante e (b) identificação das categorias, na qual a experimentadora lia uma história para o participante e apresentava um protocolo de ensino, que continha três questões de múltipla escolha, apresentadas uma a uma, com quatro alternativas cada. As questões foram planejadas de forma que a primeira apresentasse estímulos bastante discrepantes entre si e as demais avançassem para discriminações cada vez mais refinadas. A cada nova categoria ensinada, eram retomados os conteúdos das categorias trabalhadas anteriormente, na forma de perguntas e respostas. Este procedimento era repetido até que o ensino das quatro categorias fosse finalizado. Os participantes emitiram 169 respostas corretas (88\%) nas questões de múltipla escolha dos protocolos de ensino. Observou-se que a maior ocorrência de respostas incorretas (16 de um total de 23, ou seja, $70 \%$ das respostas incorretas) ocorreu nas terceiras questões de cada protocolo de ensino. As autoras argumentaram que o número de respostas incorretas poderia ter sido minimizado se a discrepância entre as alternativas de resposta tivesse sido menor, com mais questões intermediárias e se a categoria Cenário fosse dividida em três categorias: Personagem, Local e Tempo, e ressaltaram a necessidade de novos estudos que testem a inserção de questões intermediárias na busca por uma aprendizagem "sem erros".

Ribeiro et al. (2009) utilizaram um procedimento de ensino semelhante ao de Bandini et al. (2006), acatando as sugestões de modificações destas autoras, na tentativa de investigar os efeitos da gradação da dificuldade ao longo das questões de identificação de categorias de histórias. Participaram deste estudo 8 crianças com idades entre 6 anos e 11 meses e 8 anos e 9 meses no início do estudo. Todas as crianças apresentaram desempenho igual ou inferior a 33\% de respostas corretas no pré-teste de identificação de categorias de história (Teste 0). Pós-testes com a mesma estrutura do Teste 0 foram aplicados após o ensino de cada categoria. Após o Teste 0 , tinha início o ensino das categorias, começando por Personagem. As estruturas de teste e de ensino e a formulação das questões foram baseadas no estudo de Bandini et al. (2006). A diferença neste estudo foi que a categoria Cenário foi subdividida em 3 categorias (Personagem, Local e Tempo) e o número de questões do protocolo de ensino foi ampliado de três para cinco em todas as categorias. Além disso, houve a inclusão de critério de desempenho para passagem do ensino de uma categoria para outra $(100 \%$ de respostas corretas em duas histórias consecutivas) e incluíram-se palavras-chave ou expressões que explicitassem a presença das seis categorias em todas as histórias utilizadas. Tais palavras ou expressões foram denominadas jargões (Ribeiro et al., 2009) e hipotetizou-se que sua presença facilitaria o ensino da discriminação das categorias estruturais de história. Por exemplo, para a categoria Personagem, foi utilizado o jargão "participaram da história (nome do personagem ou personagens)". Para a categoria Tema, foi utilizado o jargão "(nome do personagem) tinha um problema: (descrição do problema)". Os dados mostram que o procedimento resultou em uma maior porcentagem de respostas corretas durante o ensino de identificação das categorias (94\%) quando comparadas às porcentagens de respostas corretas dos participantes no estudo de Bandini et al. (2006; 88\%). Além disso, apesar das autoras terem sugerido uma independência funcional entre os repertórios de identificação de cada categoria, observou-se que todos os participantes mostraram a emergência de, pelo menos, uma categoria após o ensino de outra categoria. As categorias nas quais se observou emergência antes de seu ensino foram Tempo, Enredo e Resolução. Para exemplificar, três participantes mostraram a emergência, assim como a manutenção da categoria Tempo, logo após o ensino de Personagem. Tais resultados mostram, diferentemente do sugerido por Ribeiro et al. (2009), uma possível dependência funcional entre as categorias. Por 
Sella, A. C., Ribeiro, D. M., Bandini, C. S. M., Bandini, H. H. M. \& Bomfim, F. M. S. (2013). Efeitos de um Programa de Ensino de Discriminação de Categorias Estruturais Implícitas de Histórias em Crianças.

essa razão, replicações e o aprimoramento do procedimento de ensino podem ser úteis para que se identifique as variáveis responsáveis pela (in)dependência funcional entre as categorias estruturais de histórias.

Embora o procedimento de Ribeiro et al. (2009) tenha sido eficiente para o ensino de categorias explícitas de histórias, tais categorias nem sempre estão explícitas nas narrativas encontradas no cotidiano, exigindo a aprendizagem da habilidade de inferí-las. Portanto, um segundo passo na programação de ensino da identificação das categorias seria o ensino das categorias quando elas aparecem de forma implícita, conforme já sugerido na literatura da área de compreensão de leitura (Lahey, McNees, \& Brown, 1973). Além disso, a replicação do procedimento de Ribeiro et al. (2009), com a modificação de apenas uma variável (categorias implícitas) pode estender a análise acerca da (in)dependência funcional entre categorias.

O objetivo do presente relato é apresentar os resultados de dois estudos que pretenderam replicar o procedimento de Ribeiro et al. (2009), contudo, agora investigando os efeitos de um procedimento de ensino de identificação de categorias estruturais de histórias, quando estas categorias aparecem de forma implícita nas narrativas. Estes estudos também pretenderam estender a análise dos resultados acerca de uma possível dependência ou independência funcional entre as categorias.

A diferença entre os Estudos 1 e 2 foi o controle do intervalo de tempo entre as sessões de ensino. Este controle deveu-se ao fato de que durante o Estudo 1 diversas greves ocorreram no sistema público de ensino de Alagoas e, desta forma, longas pausas ocorreram durante sua coleta. Como a literatura ressalta diversos efeitos que a simples passagem do tempo pode ter quando se tem em vista a validade interna e externa de um experimento (p. ex., Campbell \& Stanley, 1963; Kabacoff, \& Girden, 2010), buscou-se com o Estudo 2 replicar o procedimento do Estudo 1, agora em uma escola particular de pequeno porte e do mesmo bairro, a fim de se verificar se os resultados obtidos no Estudo 1 poderiam ser confirmados.

\section{Método}

\section{Estudo 1}

\section{Participantes}

Participaram do Estudo 1 seis crianças de uma escola pública da cidade de Maceió, sendo três meninos e três meninas com idades entre 11 anos e 3 meses e 12 anos e 8 meses de idade no início do estudo. A escola fica localizada em um bairro de baixa renda do município e as famílias dos participantes foram classificadas como pertencentes a Classe $\mathrm{E}$ (renda familiar de até $\mathrm{R} \$ 415,00$ ), segundo dados da Associação Brasileira de Empresas de Pesquisa (ABEP, 2009). Todos os participantes apresentavam dificuldades na produção de textos, segundo a professora. A Tabela 1 traz a caracterização detalhada dos participantes.

Tabela 1

Caracterização dos Participantes dos Estudos 1 e 2 e Resultados Obtidos nos Pré-Testes

\begin{tabular}{ccccc}
\hline Participantes & & Gênero & Idade $^{\mathrm{a}}$ & \% Respostas Corretas Pré-Teste \\
\hline Estudo 1 & Davi & Masculino & 11,7 & 0 \\
& João & Masculino & 11,8 & 0 \\
& Joel & Masculino & 11,6 & 17 \\
& Tati & Feminino & 11,3 & 33 \\
& Juju & Feminino & 12,8 & 33 \\
& Teia & Feminino & 12,3 & 33 \\
Estudo 2 2 & Paty & Feminino & 9,2 & 33 \\
& Jadi & Feminino & 8,11 & 33 \\
& Kely & Feminino & 9,5 & 33 \\
& Dudu & Masculino & 10,2 & 0 \\
& Alba & Feminino & 9,6 & 17 \\
& Rafa & Masculino & 9,8 & 17 \\
\hline
\end{tabular}

Nota. ${ }^{\mathrm{a} E m}$ anos e meses no início do estudo.

Os procedimentos deste estudo, bem como os do Estudo 2, foram aprovados pelo Comitê de Ética em Pesquisa com Seres Humanos da Universidade Estadual de Ciências da Saúde de Alagoas (protocolo \#941) e executados com os cuidados necessários para garantir o bem-estar dos participantes e evitar sua exposição a riscos de qualquer natureza.

\section{Ambiente e Materiais}

O estudo foi conduzido individualmente em uma sala de aula da escola dos participantes. Duas carteiras foram posicionadas uma de frente para outra, uma para a experimentadora e a outra para o participante. Foram utilizados giz de cera, recortes de jornais e adesivos. 


\section{Estímulos Experimentais}

Foram utilizadas 46 histórias escritas pelas autoras, especialmente planejadas de modo a incluir conteúdos relativos a todas as categorias. As histórias foram planejadas de modo que as categorias Personagem, Local e Tempo aparecessem duas vezes e que as categorias Tema, Enredo e Resolução aparecessem apenas uma vez em cada história. Nenhuma história continha o uso de jargões fornecendo dicas acerca da presença das categorias estruturais.

Foram utilizados dois Conjuntos de Questões de Múltipla Escolha ao longo do procedimento, sendo que o primeiro conjunto foi apresentado durante os pré e pós-testes e o segundo, durante o ensino de cada categoria estrutural. O primeiro conjunto consistia em seis questões, cada uma com quatro alternativas. As seis questões eram divididas de modo que cada categoria estrutural aparecesse na forma de uma das alternativas de múltipla escolha, quatro vezes ao longo do conjunto. Não havia consequências programadas específicas para respostas corretas e incorretas, apenas a apresentação da próxima tentativa após cada resposta do participante. O segundo conjunto de questões continha cinco questões de múl- tipla escolha, apresentadas separadamente, com quatro alternativas cada. Dentre as quatro alternativas possíveis na questão 1, uma continha a resposta correta e as outras três continham informações muito diferentes das contidas na história (informações que poderiam ser consideradas "absurdas"). Na questão 2, foram apresentadas a resposta correta, duas alternativas "absurdas" utilizadas na questão anterior e uma alternativa com informações "similares" às contidas na história, porém não correta. Na questão 3, além da resposta correta, foram apresentadas uma alternativa "absurda", uma alternativa "similar" ambas presentes na questão anterior, e uma alternativa contendo uma das categorias estruturais de histórias, a qual era incorreta em relação à pergunta feita, porém correta em relação à história lida. Na questão 4, foram apresentadas a resposta correta, uma alternativa "similar" presente na questão 3 e duas alternativas com outras categorias pertencentes à história (uma delas estava presente na questão 3), porém incorretas em relação à pergunta feita. Para finalizar, na questão 5, foram apresentadas apenas alternativas com conteúdos das categorias, porém apenas uma delas era correta para a pergunta feita. Um exemplo das questões apresentadas durante a fase de ensino se encontra na Tabela 2.

Tabela 2

Conjunto de Questões de Múltipla Escolha de Ensino Relativo à História “A Casa de Carla”, Apresentada no Ensino da Categoria Personagem

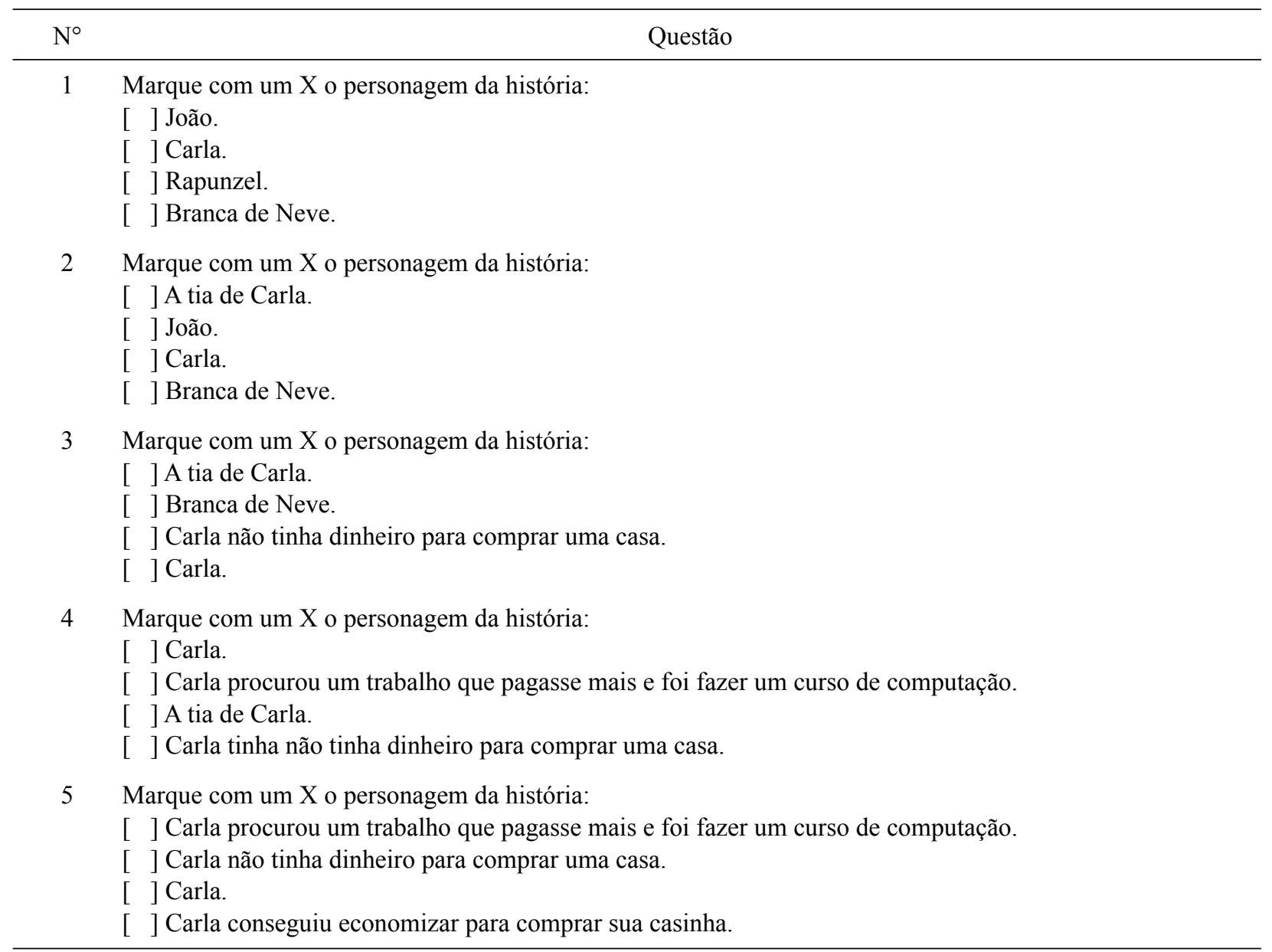

Nota. As alternativas corretas são as que contêm "Carla" como personagem. 
Sella, A. C., Ribeiro, D. M., Bandini, C. S. M., Bandini, H. H. M. \& Bomfim, F. M. S. (2013). Efeitos de um Programa de Ensino de Discriminação de Categorias Estruturais Implícitas de Histórias em Crianças.

Além das histórias e dos conjuntos de questões, cada criança possuía uma Folha para Atividades, que eram folhas de papel A4 divididas em seis partes iguais, sendo que cada divisão se destinava a uma categoria estrutural de história.

\section{Delineamento Experimental e Procedimento Geral}

Foi empregada a lógica de um delineamento de múltiplas sondas (p. ex., Barlow, Nock, \& Hernsen, 2009; Kazdin, 1982) entre categorias, isso porque houve a avaliação de todas as categorias antes e após o ensino de cada uma delas. Neste primeiro estudo, o objetivo era que a coleta de dados fosse completada em três meses. Contudo, devido a greves no sistema público de ensino de Alagoas, as sessões foram conduzidas durante um período de 8 meses. A seguir, segue a descrição detalhada dos testes e das fases de ensino.

\section{Pré-Teste e Pós-Testes de Categorias Estruturais Implícitas de História}

O pré-teste avaliava o repertório inicial de identificação de categorias estruturais implícitas, após a seguinte instrução: "Agora vou contar uma história para você. Vou contar esta história duas vezes. Preste atenção porque depois vamos fazer alguns exercícios sobre a história". Em seguida, a experimentadora lia a história duas vezes e fornecia a seguinte instrução

Agora vamos fazer os exercícios sobre a história. Eu vou ler o exercício e você vai marcar um $\mathrm{X}$ na alternativa que acha correta. Espere eu ler todas as alternativas antes de escolher a que você acha que está correta.

A experimentadora, então, apresentava o conjunto de seis questões relativas ao pré-teste. O critério para participação no estudo era de, no máximo, duas respostas corretas no pré-teste.

Os pós-testes foram apresentados após o ensino de cada categoria e eram estruturalmente semelhantes aos pré-testes, porém utilizavam sempre histórias diferentes. Além disso, era solicitado aos participantes para realizarem uma atividade de representação da categoria ensinada com o objetivo de aumentar seu contato com a descrição das categorias. Cada participante possuía uma Folha para Atividades individual. Após o pós-teste de uma dada categoria, o participante preenchia a divisão correspondente. O preenchimento consistia na colagem de adesivos, recortes de jornais ou em um desenho que representasse a categoria aprendida. Após o preenchimento, o nome da categoria era escrito dentro da respectiva divisão da folha de atividades. Esta atividade era seguida pelo ensino da categoria seguinte.

As sessões de pré-teste tiveram duração média de 30 minutos e as sessões de pós-teste, de 45 minutos.

\section{Ensino das Categorias Estruturais}

$\mathrm{O}$ ensino das categorias estruturais foi dividido em duas fases: descrição e identificação das categorias. Cada fase teve duração média de 20 minutos.
Descrição da Categoria. Ao longo desta fase, foram utilizadas dicas verbais com atraso para ensino da descrição de cada uma das categorias de história. No início de cada sessão, a experimentadora perguntava ao participante se ele sabia a definição da categoria a ser ensinada naquela sessão e esperava por cinco segundos sua resposta. Caso não houvesse resposta ou a resposta fosse incorreta ou incompleta, a definição correta da categoria era apresentada. Perguntava-se, então, sobre a importância da categoria para a construção e compreensão de uma história. Discutia-se tal importância com o participante. Em seguida, lia-se uma história exemplo e, ao final da leitura, experimentadora e participante identificavam a categoria ensinada na história lida. Após o término desta atividade, era iniciada a fase de identificação da categoria.

Identificação da Categoria. Na identificação de cada categoria, a experimentadora lia uma história, que podia ser re-lida uma vez. Antes da leitura da história, era fornecida a instrução:

Agora, vou ler uma história para você. Depois que eu ler, você deverá responder a algumas perguntas marcando com um $\mathrm{X}$ a resposta certa. Para responder a estas perguntas, preste bastante atenção à história que vou ler. Preste muita atenção ao (nome da categoria ensinada) da história.

Após a leitura da história, as cinco questões relativas à história contada (vide descrição do segundo conjunto de questões de múltipla escolha) eram apresentadas individualmente. Em seguida, a descrição da categoria era reapresentada e seguida por uma nova tarefa de identificação, com uma segunda história. Se o participante emitisse $100 \%$ de respostas corretas na fase de identificação nas Histórias 1 e 2, era apresentado o pós-teste da categoria. Caso não atingisse o critério, o procedimento era reapresentado com novas histórias em uma nova sessão (descrição e identificação) até que se observasse $100 \%$ de respostas corretas em duas histórias consecutivas.

\section{Estudo 2}

\section{Participantes}

Participaram do Estudo 2 seis crianças de uma escola privada na cidade de Maceió, com dificuldades na produção de textos, segundo a professora, sendo três meninos e três meninas com idades entre 8 anos e 1 mês e 10 anos e 11 meses no início do estudo. Estes participantes eram moradores do mesmo bairro dos participantes do Estudo 1 e suas famílias foram classificadas como pertencentes as Classes E e D (renda familiar de até R $\$ 415,00$ e $\mathrm{R} \$ 680,00$, respectivamente), segundo a ABEP (2009). A Tabela 1 traz a caracterização dos participantes do Estudo 2.

As demais etapas do procedimento foram rigorosamente idênticas as do procedimento do Estudo 1. 


\section{Resultados e Discussão}

Primeiramente, é importante ressaltar o fato de que a coleta de dados do Estudo 1 ocorreu ao longo de oito meses, com intervalos entre as aplicações do procedimento que chegaram a durar mais do que um mês. Conforme ressaltado por Barlow et al. (2009) e Campbell e Stanley (1963), a passagem do tempo implica em ameaças à validade interna de estudos devido a influência de variáveis como história de aprendizagem e maturação do indivíduo. Da mesma forma, Pelaez-Nogueras e Gewirtz (1997), dentre outros autores, afirmam que mudanças no comportamento acontecem devido a interações contínuas entre o indivíduo e variáveis ambientais. Delineamentos experimentais de sujeito único permitem o monitoramento (porém não impedem a interferência) dessas variáveis devido a medidas repetidas e frequentes da variável dependente. Na tentativa de refinar o controle experimental, o Estudo 2 consistiu na replicação do procedimento utilizado no Estudo $1 \mathrm{com}$ a alteração de uma variável: o intervalo entre as sessões teve duração máxima de uma semana. Dessa maneira, o Estudo 2 foi conduzido em uma escola particular localizada no mesmo bairro em que o Estudo 1 e a coleta de dados foi realizada ao longo de 4 meses.

A seguir, é apresentada uma breve descrição dos efeitos gerais do procedimento sobre o desempenho dos participantes. Logo após, são descritos detalhadamente (a) o desempenho dos participantes no pré-teste, (b) ao
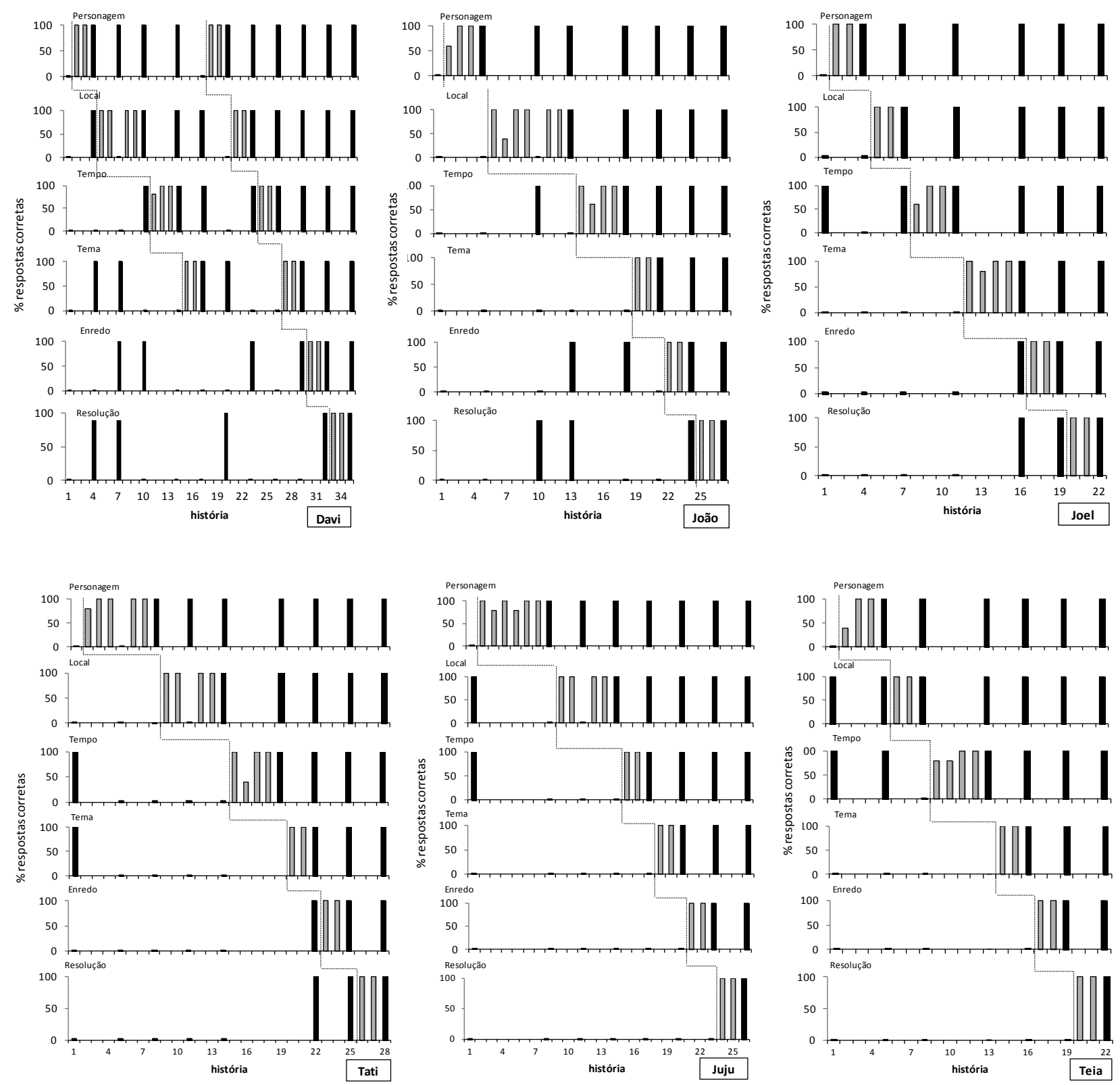

Figura 1. Porcentagens de Respostas Corretas por História, Durante o Ensino (Barras Cinzas) e nos Pré e Pós-Testes de Identificação (Barras Pretas) das Categorias Estruturais de História dos Participantes do Estudo 1. 
Sella, A. C., Ribeiro, D. M., Bandini, C. S. M., Bandini, H. H. M. \& Bomfim, F. M. S. (2013). Efeitos de um Programa de Ensino de Discriminação de Categorias Estruturais Implícitas de Histórias em Crianças.

longo do ensino e (c) nos pós-testes das categorias. Em seguida, discute-se a questão da emergência de categorias não diretamente ensinadas e propõe-se um novo delineamento experimental para futuros estudos. Posteriormente, analisa-se o número total de histórias apresentadas a cada participante até o alcance do critério de desempenho no ensino. Além disso, discute-se a eficácia do procedimento ao se comparar o número de respostas corretas em relação ao número de respostas incorretas ao longo do ensino.
O procedimento resultou na aprendizagem de todas as categorias, por todos os participantes, conforme ilustrado nas Figuras 1 e 2. Todavia, foram observadas diferenças individuais: (a) no número de respostas corretas no pré-teste, (b) no número de histórias necessário até o alcance de critério de desempenho, (c) no número de categorias que emergiram sem ensino direto e (d) no número de respostas incorretas emitidas ao longo do procedimento.
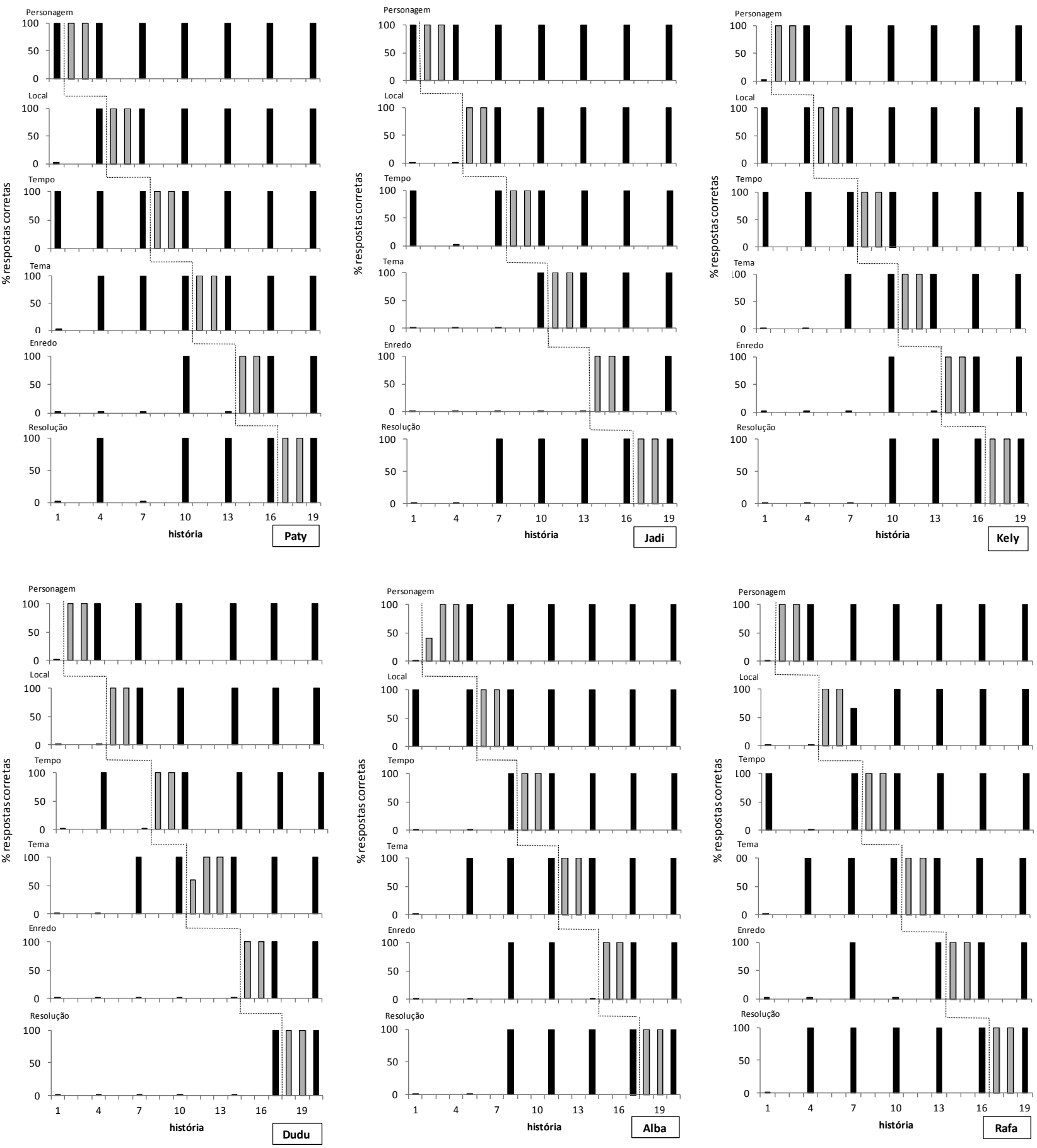

Figura 2. Porcentagens de Respostas Corretas por História, Durante o Ensino (Barras Cinzas) e nos Pré e Pós-Testes de Identificação (Barras Pretas) das Categorias Estruturais de História dos Participantes do Estudo 2. 
Como pode ser observado nas Figuras 1 e 2, Davi, João e Dudu emitiram respostas incorretas em todas as questões do pré-teste (história 1). Os demais participantes emitiram respostas corretas em uma (Joel, Alba e Rafa) ou duas (Tati, Juju, Teia, Paty, Jadi e Kely) questões. As respostas corretas, nestes casos, aconteceram em sua maioria nas categorias Personagem, Local e Tempo. $\mathrm{O}$ fato de alguns participantes terem mantido respostas corretas para essas categorias ao longo de todos os pós-testes pode indicar que estes já identificavam estas categorias antes da introdução do procedimento de ensino: Alba emitiu (e manteve) $100 \%$ de respostas corretas antes do ensino de Local; Paty emitiu (e manteve) 100\% de respostas corretas antes do ensino de Tempo; e Kely emitiu (e manteve) $100 \%$ de respostas corretas antes do ensino de Local e de Tempo. Apesar da manutenção de respostas corretas emitidas pelos participantes acima citados, é importante notar que, especialmente na categoria Tempo, dentre as oito respostas corretas que foram emitidas no pré-teste (por oito participantes diferentes), seis não se mantiveram em todos os pós-testes que foram apresentados antes do ensino desta categoria. A não-manutenção de $100 \%$ de respostas corretas antes do ensino direto da categoria permite também a inferência de que a história do pré-teste pode ter fornecido dicas que ocasionaram as respostas corretas. Outra questão a ser considerada em relação à categoria Personagem diz respeito ao fato de que, como apenas uma sonda foi apresentada antes do ensino dessa categoria, não é possível fazer inferências acerca do desempenho dos participantes: os participantes já sabiam identificar esta categoria? Suas respostas foram ao acaso? A história forneceu dicas que ocasionaram a resposta correta? Duas mudanças seriam importantes para avaliar melhor os desempenhos no pré-teste: a primeira delas se refere à adoção de um delineamento experimental de sondas múltiplas entre categorias, o qual inclui a apresentação de pré-testes até haver estabilidade no desempenho dos participantes, conforme sugerido por Cooper, Heron e Heward (2007). Neste tipo de delineamento, pelo menos três sondas são aplicadas antes da introdução da variável independente, permitindo inferências adicionais acerca do repertório comportamental inicial dos participantes e acerca do tipo de controle que as histórias podem exercer sobre seu comportamento. Estes dados podem guiar a condução do experimento ao evitar, inclusive, que se exponha os participantes ao ensino de habilidades que já se encontram presentes em seu repertório. A segunda mudança seria a construção de um delineamento que permitisse comparar desempenhos no pré-teste utilizando-se a mesma história, mas com mudanças nas partes da história do pré-teste relativas às categorias nas quais houve respostas corretas. Se os participantes emitissem respostas corretas mesmo com as mudanças nas histórias, poder-se-ia inferir que as respostas-alvo já faziam parte de seu repertório e não eram nem derivadas de dicas presentes na história, nem fruto do acaso.
Em relação ao desempenho dos participantes ao longo do ensino e pós-testes das categorias, as Figuras 1 e 2 ilustram os resultados dos Estudos 1 e 2, respectivamente. Para Davi (Figura 1), foi necessário o re-ensino de categorias e/ ou mais do que duas histórias para alcance do critério de desempenho nas categorias Local, Tempo, Personagem e Tema. Mais especificamente, ele identificou a categoria Personagem incorretamente no pós-teste de Tema, sendo necessário o re-ensino dessa categoria (histórias 18 e 19). Além disso, no pós-teste que seguiu o re-ensino de Personagem, Davi emitiu respostas incorretas para as categorias Local e Tempo, sendo necessário o re-ensino destas categorias (histórias 21 e 22 e histórias 24 e 25 , respectivamente). Neste segundo pós-teste de Tempo, emitiu resposta incorreta para a categoria Tema (história 26). Por essa razão, foi novamente exposto ao ensino desta categoria, no qual alcançou o critério de desempenho em duas histórias (histórias 27 e 28).

Dentre os resultados de Tati (Figura 1), destaca-se o fato de que nos pós-testes, introduzidos após o ensino das categorias Personagem (história 5) e Local (história 11), ela emitiu respostas incorretas para essas categorias, sendo necessárias duas histórias adicionais para alcance de critério (histórias 6 e 7 e histórias 12 e 13, respectivamente). Nos demais pós-testes, a participante identificou corretamente todas as categorias previamente ensinadas.

Em relação aos dados de João (Figura 1), vale ressaltar que, no pós-teste introduzido imediatamente após o ensino de Local, ele emitiu resposta incorreta para essa categoria (história 10). Por essa razão, foi exposto a outras duas histórias para re-ensino de Local (histórias 11 e 12). Nos demais pós-testes, ele emitiu respostas corretas para as categorias previamente ensinadas. Assim como João, Juju (Figura1) emitiu resposta incorreta para Local no pós-teste dessa categoria (história 11), foi exposta a seu re-ensino, no qual alcançou critério após a apresentação de mais duas histórias (histórias 12 e 13), e emitiu respostas corretas diante das categorias previamente ensinadas nos demais pós-testes.

Em relação a Joel (Figura1), destaca-se o fato de que após alcance de critério no ensino de cada uma das categorias, ele emitiu respostas corretas diante de todas as categorias previamente ensinadas, sendo assim, não houve re-ensino para este participante. Resultados semelhantes foram observados em Teia (Figura1), que também foi exposta a todo procedimento sem a necessidade de re-ensino de nenhuma categoria.

No Estudo 2, como pode ser observado na Figura 2, salvo duas exceções, foi necessária a apresentação do número mínimo de histórias (duas) para alcance de critério de desempenho no ensino de cada uma das categorias. As duas exceções foram observadas em Dudu e em Alba, os quais alcançaram o critério de desempenho com três histórias no ensino das categorias Tema e Personagem, respectivamente. 
Sella, A. C., Ribeiro, D. M., Bandini, C. S. M., Bandini, H. H. M. \& Bomfim, F. M. S. (2013). Efeitos de um Programa de Ensino de Discriminação de Categorias Estruturais Implícitas de Histórias em Crianças.

Nos pós-testes, introduzidos após alcance de critério de desempenho no ensino de cada uma das categorias, todos os participantes do Estudo 2 emitiram respostas corretas para as categorias previamente ensinadas. Além disso, como pode ser observado na Figura 2, todos mostraram a emergência de categorias não ensinadas.

No pós-teste da categoria Personagem, Paty mostrou a emergência das categorias Local e Tema e, após o ensino de Tempo, a emergência da categoria Resolução. Jadi mostrou a emergência das categorias Tempo e Resolução no pós-teste que seguiu o ensino de Local e a emergência de Tema, após o ensino de Tempo. Os dados de Kely mostram a emergência da categoria Tema no pós-teste que seguiu o ensino de Local e, de Resolução após o ensino de Tempo. O desempenho de Alba indica a emergência de Tema após o ensino de Personagem e das categorias Tempo e Resolução no pós-teste que seguiu o ensino de Local. Os dados de Rafa indicam a emergência das categorias Tema e Resolução após o ensino de Personagem, Tempo após o ensino de Local e Enredo após o ensino de Tema. Finalmente, Dudu identificou corretamente as categorias Tema e Resolução antes dessas serem ensinadas, sendo que a primeira emergiu após o ensino de Local e a segunda após o ensino de Enredo.

A emergência de respostas corretas de identificação de categorias antes de seu ensino também foi observada nos participantes do Estudo 1. Joel identificou corretamente as categorias Tema, Enredo e Resolução antes de essas serem ensinadas, sendo que Tema emergiu após o ensino de Local e Enredo e Resolução emergiram após o ensino de Tema. Davi e Tati mostraram a emergência de duas categorias. Davi identificou corretamente a categoria Enredo após o re-ensino da categoria Tema e identificou corretamente Resolução após o ensino de Enredo. Tati mostrou a emergência das categorias Enredo e Resolução após o ensino de Tema. João e Teia identificaram corretamente uma categoria antes do ensino, sendo que João mostrou a emergência de Resolução após o ensino de Enredo e Teia identificou corretamente a categoria Local já no pré-teste. Juju foi a única participante que não emitiu respostas corretas em pós-testes de categorias que ainda não haviam sido ensinadas.

A partir desses resultados, observa-se que a categoria que emergiu após o pré-teste e se manteve antes de seu ensino com mais frequência foi Resolução. Dentre as 10 respostas corretas emitidas para essa categoria antes de seu ensino, três foram observadas após o ensino da categoria Enredo, duas após o ensino das categorias Local, Tempo e Tema e uma após o ensino de Personagem. É possível que a categoria Resolução tenha emergido mais frequentemente em virtude do fato de seu nome ser auto-explicativo. Em outras palavras, resolução refere-se à solução de um problema, explicitando a informação requerida pela questão apresentada no segundo Conjunto de Questões de Múltipla Escolha, apresentado nos pós-testes. A explicitação da resposta, associada à provável presença de relações previamente estabelecidas no repertório dos participantes (entre o nome "resolução" e sua descrição), pode ter sido a variável responsável pela emissão de respostas corretas para a categoria Resolução antes de seu ensino.

Foi sugerido anteriormente que se adote um delineamento de sondas múltiplas para aumento do controle experimental. Além disso, o fato de diversas categorias terem emergido antes de seu ensino direto sugere uma perda de controle experimental que a simples presença de sondas múltiplas entre categorias não seria capaz de evitar. A adoção de um delineamento experimental de sondas múltiplas, mas que esteja inserido em um delineamento experimental entre participantes será a melhor forma de obter controle experimental: permite-se o monitoramento da aprendizagem e/ou a emergência de cada categoria, ao mesmo tempo em que o controle entre participantes é mantido (as categorias poderão emergir sem ensino direto para um dado participante, mas o controle será mantido entre participantes).

Em relação ao número total de histórias apresentadas durante o ensino, verifica-se que, para quatro participantes do Estudo 2 (Paty, Jadi, Kely e Rafa), foi necessário o número mínimo de histórias (12 histórias) para alcance de critério de desempenho no ensino das categorias. Davi foi aquele que foi exposto ao maior número de histórias (23), seguido por João e Tati (19 histórias), Juju (18 histórias), Joel e Teia (15 histórias) e Dudu e Alba (13 histórias). A apresentação do menor número de histórias para a maior parte dos participantes do Estudo 2 pode estar associada ao menor espaçamento de tempo entre as sessões neste estudo. Uma comparação entre os resultados do pré-teste e o número de histórias apresentadas durante o ensino mostra que o melhor desempenho no pré-teste ( 2 respostas corretas) não parece estar necessariamente relacionado a um menor número de histórias para alcance de critério: alguns participantes com mais respostas corretas no pré-teste estão entre aqueles que foram expostos a mais histórias antes do alcance de critério. Além disso, para a maior parte dos participantes que foram expostos a mais do que duas histórias durante o ensino de uma dada categoria, foram apresentadas mais histórias no ensino das três primeiras categorias (Personagem, Local e Tempo). Este fato vai ao encontro da literatura acerca de learning sets (p. ex., Harlow, 1949) a qual descreve que a aprendizagem de comportamentos semelhantes se torna mais rápida conforme 0 indivíduo é exposto a novos exemplares.

Em relação às respostas incorretas emitidas durante 0 ensino ao longo do Estudo 1, observou-se um total de 22 respostas incorretas ( $4 \%$ das respostas emitidas), sendo que 10 ocorreram na categoria Tempo, 8 na categoria Personagem, 3 na categoria Local e 1 na categoria Tema. Mais especificamente, no que se refere às questões apresentadas durante o ensino (todas as histórias continham cinco questões), a maior parte das respostas incorretas concentrou-se nas questões 3 e 4 , sendo que foram observadas sete respostas incorretas em cada uma delas. Além disso, foram observadas quatro respostas corretas na questão 2 , três na questão 5 e uma na questão 1. No Estudo 2, observou-se 
cinco respostas incorretas $(2 \%)$ em relação a um total de 370 questões as quais ocorreram nas questões 4 e 5 da primeira história apresentada no ensino da categoria Tema e nas questões 2, 3 e 5 da primeira história apresentada para o ensino de Personagem. Assim como nos estudos de Bandini et al. (2006), Maranhe (2004) e Ribeiro e et al. (2009), o procedimento de ensino mostrou-se bastante efetivo, tendo em vista que, no mínimo, $96 \%$ das respostas emitidas foram corretas. De forma geral, houve uma maior concentração de respostas incorretas nas categorias Tempo e Personagem. Sugere-se que futuros estudos façam modificações, tanto nas histórias, quanto nas questões, e testem se há uma diminuição na quantidade de respostas incorretas apresentadas. Uma possibilidade é modificar as questões de múltipla escolha, de maneira a incluir mais um passo intermediário no estabelecimento da discriminação da resposta correta. Nos presentes estudos, alternativas absurdas, similares e com outras categorias, diferentes da categoria ensinada, foram apresentadas juntamente com a resposta correta. $\mathrm{O}$ acréscimo de um quarto tipo de alternativa incorreta, a qual contenha a categoria correta e uma informação irrelevante à história, pode facilitar a aquisição da discriminação da categoria ensinada e, por consequência, a um menor número de erros.

Os resultados apresentados estendem os resultados obtidos por Bandini et al. (2006) e Ribeiro et al. (2009), mostrando que o ensino da identificação das categorias estruturais de histórias pode favorecer a aprendizagem do repertorio de discriminação destas categorias. Estudos futuros podem aprimorar o procedimento descrito conforme os aspectos mencionados anteriormente, inclusive, levando-se em consideração que seria importante a existência testes de manutenção do repertório ensinado, após o término do estudo.

\section{Referências}

Aulete, C. (Ed.). (2006). Dicionário Contemporâneo da Língua Portuguesa. Rio de Janeiro, RJ: Lexikon Editora Digital.

Associação Brasileira de Empresas de Pesquisa. (2009). Critério de classificação econômica: Brasil. Recuperado em 11 de outubro, 2011, de http://www.abep.org/novo/Content. aspx?ContentID $=301$

Ballard, K. D., \& Glynn, T. (1975). Behavioral self-management in story writing with elementary school children. Journal of Applied Behavior Analysis, 8(4), 387-398.

Bandini, C. S. M., Sella, A. C., \& de Souza, D. G. (2006). Considerações acerca do planejamento de procedimentos de ensino de discriminações complexas. In H. J. Guilhardi \& N. C. de Aguirre (Eds.), Sobre comportamento e cognição: Expondo a variabilidade (Vol. 17, pp. 61-71). Santo André, SP: Esetec.

Banks-Wallace, J. (1999). Storytelling as a tool for providing holistic care to women. American Journal of Maternal Child Nursing, 24(1), 20-24.

Barlow, D., Nock, M., \& Hersen, M. (2009). Single case experimental designs: Strategies for studying behavior for change ( $3^{\text {rd }}$ ed.). Boston, MA: Pearson Education.

Campbell, D. T., \& Stanley, J. C. (1963). Experimental and quasi-experimental designs for research. Chicago, IL: Rand McNally College.
Cooper, J. O., Heron, T. E., \& Heward, W. L. (2007). Applied behavior analysis ( $2^{\text {nd }}$ ed.). Upper Saddle River, NJ: Pearson.

Glover, J. A. (1979). The effectiveness of reinforcement and practice for enhancing the creative writing of elementary school children. Journal of Applied Behavior Analysis, 12(3), 487.

Harlow, H. F. (1949). The formation of learning sets. Psychological Review, 56, 51-65.

Kabacoff, R., \& Girden, E. R. (2010). Evaluating research articles from start to finish. London: Sage.

Kazdin, A. E. (1982). Single-case research designs: Methods for clinical and applied settings. New York, NY: Oxford Press.

Koki, S. (1998). Storytelling: The heart and soul of education. Pacific Resources for Education and Learning, 1-4.

Lahey, B. B., McNees, M. P., \& Brown, C. (1973). Modification of deficits in reading for comprehension. Journal of Applied Behavior Analysis, 6(3), 475-480.

Mandler, J. M., \& Johnson, N. S. (1977). Remembrance of things parsed: Story structure and recall. Cognitive Psychology, 9, 111-151.

Maranhe, E. A. (2004). Ensinando categorias estruturais de história a crianças com dificuldades de aprendizagem (Tese de doutorado, Universidade Federal de São Carlos, SP, Brasil).

Pelaez-Nogueras, M., \& Gewirtz, J. (1997). The context of stimulus control in behavior analysis. In D. M. Baer \& E. M. Pinkston (Eds.), Environment and behavior (pp. 30-42). Boulder, CO: Westview Press.

Ribeiro, D. M., Pascualon, J. F., Sella, A. C., Bandini, C. S. M., $\&$ de Souza, D. G. (2009). Avaliação de um procedimento para ensinar categorias estruturais de histórias. Revista Psicologia Escolar e Educacional, 13(2), 303-314.

Spinillo, A. G., \& Simões, P. U. (2003). O desenvolvimento da consciência metatextual em crianças: Questões conceituais, metodológicas e resultados de pesquisa. Psicologia: Reflexão e Crítica, 16(3), 537-546.

Stein, N. L. (1982). The definition of a story. Journal of Pragmatics, 6(5-6), 487-507. doi: 10.1016/0378-2166(82)90022-4 